\title{
Intermedin is upregulated and has protective roles in a mouse ischemia/reperfusion model
}

\author{
Heng-yu Zhang ${ }^{1,2,4}$, Wei Jiang ${ }^{2,3,4}$, Jian-Ying $\mathrm{Liu}^{2}$, Yan $\mathrm{Li}^{2}$, Chun-Lin Chen ${ }^{2}$, Hong-Bo Xin ${ }^{2,3}$ \\ and De-Jia Huang ${ }^{1}$
}

Intermedin (IMD), a new calcitonin/calcitonin gene-related peptide family peptide with vasodilatory and positive inotropic properties, has multiple functions in regulating cardiovascular homeostasis and is of particular interest in the pathophysiology of myocardial ischemia/reperfusion (MI/R). We created a mouse model of MI/R by ligating the cardiac left anterior descending artery to study the possible pathophysiological role of IMD and its receptor complexes in MI/R. Compared with the control, infarcted mice showed increased content, mRNA and protein expression of IMD in plasma and cardiac tissue. The mRNA expression of the receptor activity-modifying protein 3 (RAMP3) gene increased very early, and the calcitonin receptor-like receptor and RAMP2 mRNA levels increased later after reperfusion. However, the RAMP1 gene expression did not change. The tissue IMD content was positively correlated with the diastolic blood pressure and negatively correlated with pulse pressure. In addition, exogenous IMD treatment significantly ameliorated the MI/R injury by rescuing the pulse pressure, inhibiting neutrophil infiltration in the peri-infarction area, and decreasing the creatine kinase and lactate dehydrogenase activities in plasma. Our results indicated that IMD was upregulated in the ischemic myocardium and may induce important beneficial cytoprotection against cardiac ischemic injury.

Hypertension Research (2009) 32, 861-868; doi:10.1038/hr.2009.120; published online 14 August 2009

Keywords: calcitonin receptor-like receptor; ischemia/reperfusion; intermedin; receptor activity-modifying proteins

\section{INTRODUCTION}

Myocardial infarction is the chief cause of death in North America and Europe. ${ }^{1}$ It results from severe impairment of the coronary blood supply, which is usually provoked by thrombotic or other acute alterations of the coronary atherosclerotic plaques. ${ }^{2}$ A loss of oxygen supply leads to apoptosis and necrosis of cardiac myocytes in the ischemic area, resulting in decreased cardiac function. ${ }^{3,4}$ Rapid reperfusion is essential to limit the extent of myocardial infarction. ${ }^{4}$ However, the consequences of reperfusion are complex and include various deleterious effects collectively referred to as ischemia/reperfusion (I/R) injury. ${ }^{3,4}$ Myocardial I/R diseases (MI/R) involve many autocrine and/or paracrine factors, such as cytokines and growth factors. ${ }^{5,6}$ Mounting evidence suggests that the altered expression of these factors may have an important regulatory role in the response to myocardial injury. ${ }^{6}$ Locally acting mediators affect not only the contractile force but also the remodeling process after myocardial injury. 5 Therefore, pharmacological agonists and antagonists that mimic the autocrine/paracrine factors have been intensively studied as potential therapies for cardiac diseases. ${ }^{6,7}$

Intermedin (IMD) was identified as a novel calcitonin/calcitonin gene-related peptide (CGRP) family member based on the analysis of multiple vertebrate genomes. ${ }^{89}$ It was shown to be a multifunctional peptide involved in regulating cardiovascular function, including potently dilating systemic and pulmonary vessels, influencing regional blood flow, augmenting cardiac contractility, and increasing urinary flow and urinary sodium excretion. ${ }^{9,10}$ Similar to other peptides in the CGRP family, IMD signals through a type II G protein-coupled receptor complex consisting of the calcitonin receptor-like receptor (CRLR) and select receptor activity-modifying proteins (RAMPs). ${ }^{9}, 10$ Unusually, IMD also acts as a selective agonist for CRLR/RAMP1 and CRLR/RAMP3 receptors. ${ }^{9,11}$ The distribution of IMD in the cardiovascular system is compatible with a physiological role in the regulation of peripheral circulation. ${ }^{10}$ Recently, there has been increased interest in the role of endogenous IMD in cardiovascular diseases. ${ }^{10,12}$ The robust expression of IMD in the diseased cardiovascular system suggests an important influence on cardiovascular pathology. ${ }^{10,12}$ It has been reported that IMD protects the myocardium from the deleterious effects of oxidative stress ${ }^{10}$ and hypertrophic stimuli, ${ }^{12}$ which indicates an important cytoprotective role of IMD as an endogenous counter-regulatory peptide in the cardiovascular system. ${ }^{9,10,12}$

\footnotetext{
${ }^{1}$ Department of Cardiology, West China Hospital, West China Medical School, Sichuan University, Chengdu, Sichuan, PR China; ${ }^{2}$ Laboratory of Cardiovascular Diseases, West China Hospital, West China Medical School, Sichuan University, Chengdu, Sichuan, PR China and ${ }^{3}$ State Key Laboratory of Biotherapy, West China Hospital, West China Medical School, Sichuan University, Chengdu, Sichuan, PR China

${ }^{4}$ These authors contributed equally to this work.

Correspondence: Dr W Jiang or Dr HB Xin, The Laboratory of Cardiovascular Diseases, West-China Hospital, \#1 Ke Yuan 4th Road, Gao Peng Street, Chengdu 610041, China and Professor DJ Huang, Department of Cardiology, West China Hospital, West China Medical School, Sichuan University, Chengdu 610041, China. E-mails: wcumsjw72@hotmail.com or hongboxin@yahoo.com and jwhx89@163.com
}

Received 25 April 2009; revised 10 June 2009; accepted 15 June 2009; published online 14 August 2009 
Alterations in not only IMD but also its receptor complexes have been further studied to reveal the underlying signal transduction in cardiovascular diseases. ${ }^{10,13,14}$ Hirose et al. ${ }^{15}$ investigated the expression of IMD and the receptor complex components (CRLR, three types of RAMP) in the hearts of rats with congestive heart failure. They showed that the mRNA expression levels of IMD and the receptor complex components were increased, indicating that IMD signaling has a certain pathophysiological role in heart failure. Little is known about the changes in IMD and its receptors in MI/R diseases. ${ }^{10}$ In this study, a mouse model of MI/R has been created by ligating the left descending coronary artery in the heart to study the expression and the levels of IMD , and its receptor complexes in the blood and heart. We were also interested in the possible protective effects of exogenous IMD administration and in understanding the potential pathophysiological role of IMD in cardiac ischemic diseases.

\section{METHODS}

\section{Materials}

The radioimmunoassay kit for mouse IMD and the specific rabbit polyclonal antiserum against mouse IMD were purchased from Phoenix Pharmaceutical (Belmont, CA, USA). Aprotinin was purchased from Sigma (St Louis, MO, USA), trizol from Gibco BRL (Gaithersburg, MD, USA), dNTP from Clontech Laboratories (Palo Alto, CA, USA), and Moloney murine leukemia virus transcriptase, Taq and Oligo(dT)15 primer from Promega (Madison, WI, USA). All pairs of PCR primers (Table 1) were synthesized by Shenggong Biotechnology (Shanghai, China). Other chemicals and reagents were of analytical grade.

\section{Peptide synthesis}

Mouse IMD peptide (IMD8-47) with the sequence

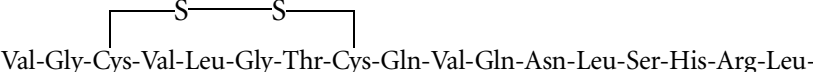
Trp-Gln-Leu-Val-Arg-Pro-Ala-Gly-Arg-Arg-Asp-Ser-Ala-Pro-Val-Asp-Pro-SerSer-Pro-His-Ser-Tyr- $\mathrm{NH}_{2}{ }^{8}$ was synthesized by ShineGene Bio-Technologies (Shanghai, China) through the solid-phase fluorenylmethoxycarbonyl method with a simultaneous multiple solid-phase peptide synthesizer (PSSM 8 system, Shimadzu, Tokyo, Japan) and analyzed by reverse phase HPLC (Agilent 1050, Agilent Technologies, Santa Clara, CA, USA) with a Cromasil C18 column and mass spectrometry using a Finnigan LCQ (Thermo/Finnigan Ltd., Waltham, MA, USA).

Animal models of myocardial infarction induced by ligation of the left anterior descending artery

Male C57BL/6 mice of 8-12 weeks (animal center, Health Sciences Center, Sichuan University) were housed under standard conditions (room temperature $20 \pm 1{ }^{\circ} \mathrm{C}$, humidity $60 \pm 10 \%$, lights from 0600 to 0180 hours) and given standard rodent chow and water freely. All experimental procedures were performed in accordance with the Guidelines for Animal Experiments from the Committee of Medical Ethics, National Health Department of China.

Mice underwent left anterior descending artery (LAD) occlusion or shamsurgery as previously described. ${ }^{3}$ Briefly, mice were anesthetized intraperitoneally with sodium pentobarbital $\left(45 \mathrm{mg} \mathrm{kg}^{-1}\right)$ and then intubated and ventilated with a rodent ventilator (Harvard Apparatus, Holliston, MA, USA). A thoracotomy was performed at the intercostal space to expose the anterior surface of the cardiac ventricle. Below the atrioventricular border, the LAD was identified and ligated by a 6.0 silk Ethilon suture. Regional ischemia was induced for $30 \mathrm{~min}$ and confirmed by the discoloration of the myocardium. Sham-operated animals were subjected to the same surgical procedures as the experimental animals, with the exception that the LAD was not ligated. At the end of ischemia, the ligature was loosened and reperfusion was performed. The lungs were reinflated, and the muscle and skin layers were closed separately. The animals were weaned from the ventilator, extubated and allowed to recover before being returned to their cages. For animals receiving IMD treatment, IMD $\left(200 \mathrm{nmol} \mathrm{kg}^{-1}\right)$ was diluted in $1 \times$ phosphate-buffered saline and injected intraperitoneally 20 min before the surgery, and $0,2,4$ and $8 \mathrm{~h}$ after reperfusion. At $48 \mathrm{~h}$ after the reperfusion, the mice were deeply anesthetized with sodium pentobarbital $\left(45 \mathrm{mg} \mathrm{kg}^{-1}\right.$, i.p.), and the mean arterial blood pressure (MABP), systolic blood pressure (SBP), diastolic blood pressure (DBP) and heart rate were measured from the left common carotid artery using an eight-channel physiological recorder (iWorx 308, iWorx/CB Sciences, Inc., Dover, NH, USA) with a carotid artery catheter. Blood was then collected from the abdominal aorta, the animals were killed by an overdose of anesthetics, and the hearts were extracted for morphometric evaluation and immunoreactive IMD (ir-IMD) assays.

\section{Morphometric evaluation of risk area and infarction size}

At $48 \mathrm{~h}$ after reperfusion, the hearts were exposed and the original sutures were re-ligated. The hearts were then perfused retrogradely with $2 \%$ Evans blue in phosphate-buffered saline ( $\mathrm{pH}$ 7.4) to delineate non-ischemic areas. Each heart was excised, and the whole left ventricle was cut into four or five sections of similar thickness perpendicular to the long axis of the heart. The sections were incubated with 1\% 2,3,5-triphenyltetrazolium chloride (Sigma Chemicals, St Louis, MO, USA) at $37^{\circ} \mathrm{C}$ for $15 \mathrm{~min}$ to demarcate viable and necrotic tissue. The thickness of each section was measured by a pair of calipers. The sections were photographed on both sides with a digital camera (Nikon, Tokyo, Japan). The infarct area (pale white), the area at risk (area excluding Evans Blue) and the total left ventricular area were traced and measured for both sides of each section using Image $\mathrm{J}$ (National Institutes of Health, Bethesda, MD, USA). The areas of each section were multiplied by the thickness of the section to obtain a measure of volume. The cumulative volumes of all sections for each heart were used for comparisons. The size of left ventricle at risk was calculated as the ratio of the left ventricle volume excluding Evans blue dye to the total left ventricle volume. Infarct size was calculated as the ratio of the infarct volume to the volume at risk, as described earlier. ${ }^{3}$

Table 1 Sequences of the oligonucleotides used for PCR amplification

\begin{tabular}{|c|c|c|c|c|c|}
\hline Target & & Sequence & Amplicon size (bp) & Annealing temperature $\left({ }^{\circ} \mathrm{C}\right)$ & Cycles \\
\hline \multirow[t]{2}{*}{ Intermedin } & Sense & 5'-A AGATCTCCACATGCACAGCTC-3' & 160 & 56 & 35 \\
\hline & Antisense & 5'-GCTCGAGTCAGCCATA ACTGT-3' & & & \\
\hline \multirow[t]{2}{*}{ CRLR } & Sense & 5'-GAAGAAGGCGTGAACCAAACAGAC-3' & 238 & 56 & 30 \\
\hline & Antisense & 5'-AGATCTTTGTAACCTTCTCTGAAGGATC-3' & & & \\
\hline \multirow[t]{2}{*}{ RAMP1 } & Sense & 5'-TGCCGGGACCCTGACTATGGGACTC-3' & 690 & 56 & 30 \\
\hline & Antisense & 5'-TTCCCAGGTTTAAGAATACTCTTTTAA-3' & & & \\
\hline \multirow[t]{2}{*}{ RAMP2 } & Sense & 5'-CAGAATCAАTCTCATCCСАCTGA-3' & 108 & 56 & 30 \\
\hline & Antisense & 5'-GTCCATGCAACTCTTGTACTCATAC-3' & & & \\
\hline \multirow[t]{2}{*}{ RAMP3 } & Sense & 5'-GGTCATTAGGAGCCACGTGT-3' & 106 & 56 & 30 \\
\hline & Antisense & 5'-GGGCTAAACAAGCCACAGCT-3' & & & \\
\hline \multirow[t]{2}{*}{ GAPDH } & Sense & 5'-ACCACAGTCCATGCCATCAC-3' & 475 & 56 & 20 \\
\hline & Antisense & 5'-TCCACСАСССTGTTGCTGTA-3' & & & \\
\hline
\end{tabular}


Lactate creatine kinase and lactate dehydrogenase activities in plasma

The activities of the plasma biochemical parameters after myocardial injury were assessed in heparinized blood. Plasma creatine kinase (CK) and lactate dehydrogenase ( $\mathrm{LDH})$ were measured using an automated clinical analyzer at the West China Hospital using clinical grade reagents.

Determination of levels of $\boldsymbol{i r}$-IMD in plasma and cardiac tissue Blood samples were taken using EDTA.Na2. $\left(1 \mathrm{mg} \mathrm{ml}^{-1}\right)$, aprotinin $(500 \mathrm{kIU})$ and heparin. The plasma was separated by centrifugation $(1600 \mathrm{~g}$ for $15 \mathrm{~min}$, $4{ }^{\circ} \mathrm{C}$ ) and stored at $-70{ }^{\circ} \mathrm{C}$ for assaying..$^{16}$ Chopped left cardiac ventricles were boiled for $10 \mathrm{~min}$ in $1 \mathrm{moll}^{-1}$ acetic acid and homogenized with a Polytron at $4{ }^{\circ} \mathrm{C}$. The extract solution was centrifuged at $24000 \mathrm{~g}$ for $30 \mathrm{~min}$. The plasma and tissue extract solution were loaded onto a Sep-Pak C18 cartridge (Phoenix Pharmaceutical) and pre-equilibrated with $0.5 \mathrm{mmoll}^{-1}$ acetic acid, and the adsorbed material was eluted with $4 \mathrm{ml}$ of $50 \% \mathrm{CH}_{3} \mathrm{CN}$ containing $0.1 \%$ trifluoroacetic acid. ${ }^{16}$ After the samples were lyophilized, the residue was dissolved in radioimmunoassay buffer and assayed according to the manufacturer's instructions. The $\mathrm{IC}_{50}$ of IMD assay was $614.60 \mathrm{pg} \mathrm{ml}^{-1}$, and the reactivity with mouse IMD was $100 \%$. No cross-reactivity was found with the mouse proadrenomedullin N-terminal 20 peptide, adrenomedullin (ADM), amylin or endothelin. The levels of ir-IMD were calculated, and are expressed as pmoll $1^{-1}$ for plasma and pmol per gram protein for tissues. ${ }^{16}$

\section{IMD immunohistochemistry}

The immunohistochemical localization of IMD was studied according to the method described earlier, ${ }^{3,16}$ with some modifications. At $48 \mathrm{~h}$ after reperfusion, the hearts were harvested and fixed in Carnoy's fluid, then cut into three sections corresponding approximately to the apex, mid-papillary and base. The sections were embedded in paraffin, cut into $4-\mu \mathrm{m}$ slices, transferred to siliconcoated slides and then treated with $3 \% \mathrm{H}_{2} \mathrm{O}_{2}$ to block endogenous peroxidase. The sections were first incubated for $1 \mathrm{~h}$ at room temperature with rabbit polyclonal anti-mouse IMD antiserum at a dilution of 1:150 and then with biotinylated goat IgG (Vector Laboratories, Burlingame, CA, USA), and IMD immunoreactivity was visualized using diaminobenzidine substrate. The presence of IMD-like immunoreactivity was indicated by a brown color in the cytoplasm. A Nikon system (Nikon) was used to capture digital images of highpower fields in the infarcted zones randomly at the different levels, and ImagePro-Plus 5.0 (Media Cybernetics, Silver Spring, MD, USA) was used to analyze the mean optical density and the area of IMD staining. The reactivities of the antiserum against IMD protein from mice, rats and humans were $100 \%$. No cross-reactivity was found with any CGRP and ADM.

\section{Reverse transcriptase-PCR study}

Gene expression levels of pro-IMD and its receptor complex components (that is, CRLR and RAMPs) were assessed by semiquantitative reverse transcriptasePCR as previously described. ${ }^{16}$ Total tissue RNAs of the control mice and ischemic mice 3 and $48 \mathrm{~h}$ after reperfusion (three in each group) were extracted and reverse transcribed. Subsequently, the products were used for PCR amplification in $25 \mu \mathrm{l}$ of a PCR reaction mixture containing $1 \mu \mathrm{l} 2.5 \mathrm{mmoll}^{-1}$ dNTP, $2.5 \mu \mathrm{l} 10 \times$ PCR buffer $\left(20 \mathrm{mmoll}^{-1} \mathrm{MgCl} 2,500 \mathrm{mmoll}^{-1} \mathrm{KCl}\right.$, $1.5 \mathrm{moll}^{-1}$ Tris- $\left.\mathrm{HCl}, \mathrm{pH} 8.7\right), 2 \mu \mathrm{cDNA}, 200 \mathrm{nmoll}^{-1}$ of the appropriate paired primers (Table 1) and $1.25 \mathrm{U}$ of Taq DNA polymerase. The PCR consisted of $20-35$ cycles at $94{ }^{\circ} \mathrm{C}$ for $30 \mathrm{~s}, 55^{\circ} \mathrm{C}$ for $30 \mathrm{~s}$ and $72{ }^{\circ} \mathrm{C}$ for $90 \mathrm{~s}$, (Table 1), followed by $74^{\circ} \mathrm{C}$ for $5 \mathrm{~min}$. As an internal control for each PCR reaction, mouse GAPDH mRNA was also amplified with each sample. All PCR products were loaded onto a $1.5 \%$ agarose-Tris-acetate-EDTA gel before electrophoresis and then visualized by ethidium bromide staining. The UV illumination photos then underwent computerized densitometric analysis (ChemiImager 5500 software, Alpha Innotech Corporation, San Leandro, CA, USA). The final results are expressed as the ratios of the PCR products to GAPDH PCR products for each sample. All experiments were repeated thrice.

\section{Histology}

To determine the numbers of infiltrating polymorphonuclear neutrophils (PMNs), sections treated as described above were cut into $4-\mu \mathrm{m}$ slices and transferred to silicon-coated slides. The tissue sections were then stained with hematoxylin and eosin. Digital images of high-power fields in the boundary area around the infarcted injury were captured randomly from the apex, midpapillary and base sections. The numbers of PMNs per high-power microscope field were independently counted by observers blinded to the treatment protocol. Average numbers of PMNs were obtained by randomly counting more than ten fields. ${ }^{17}$

\section{Statistical analysis}

Results are shown as mean \pm s.e.m. Comparisons were performed using unpaired Student's $t$-tests and one-way ANOVA. $P$-values $<0.05$ were considered statistically significant.

\section{RESULTS}

General characteristics of mice with myocardial Infarction

As shown in Table 2, after $48 \mathrm{~h}$ of reperfusion, the animals that received $\mathrm{MI} / \mathrm{R}$ treatment showed increased levels of SBP, DBP and MABP, by $+5.3,+21.4$ and $+14.6 \%$ (all $P>0.05$ ), and decreased heart rate and pulse pressure, by $-7.6 \%(P>0.05)$ and $-172.7 \%(P<0.01)$, respectively, compared with those of the control animals.

After IMD treatment, the animals showed obvious increases in heart rate and pulse pressure, by +24.3 and $+208.1 \%$ (both $P<0.01$ ), respectively, compared with $\mathrm{MI} / \mathrm{R}$ mice, and SBP, DBP and MSBP decreased by $-2.6,-22.7$ and $-13.6 \%$ (all $P>0.05$ ), respectively, compared with the MI/R group.

In addition, the $\mathrm{MI} / \mathrm{R}$ group that received IMD treatment had a clear increase in heart rate by $+15.5 \%(P<0.05)$ compared with that in the control animals, whereas no significant differences were observed in SBP, DBP, MSBP and pulse pressure between the MI/R group after IMD treatment and the control group (all $P>0.05$ ).

\section{ir-IMD contents increased in different tissues}

The plasma ir-IMD concentration in animals with sham-surgery was $41.3 \pm 5.5 \mathrm{pmoll}^{-1}(n=8)$. As shown in Figure 1, $i r$-IMD was detected in the assayed cardiac ventricle.

Compared with the control animals, the MI/R group had a $68.4 \%$ higher plasma ir-IMD concentration $\left(69.5 \pm 7.1 \mathrm{pmoll}^{-1}, P<0.01\right.$, both $n=8)$. The tissue $i r$-IMD content in the cardiac ventricle was higher than that of the control by $+230.6 \%(P<0.01)$.

\section{IMD immunohistochemistry}

Cardiac myocytes of control hearts that received sham-surgery (Figure 2) showed sporadic, positive IMD immunoreactive staining in the cytoplasm. All myocytes in the infarcted areas of $\mathrm{I} / \mathrm{R}$ hearts (Figure 2) showed intense, positive IMD staining in the cytoplasm. The mean optical density $(80514 \pm 9127$ vs. $8061 \pm 1613$, both $n=4)$

Table 2 Blood pressure and heart rate in mice without or with IMD treatment (mean \pm s.e.m., $n=8$ )

\begin{tabular}{lccc}
\hline & Control & I/R & I/R+IMD \\
\hline Heart rate (b.p.m.) & $391 \pm 14$ & $363 \pm 13$ & $451 \pm 26^{*}$,\#\# \\
SBP (mm Hg) & $128 \pm 6$ & $135 \pm 12$ & $132 \pm 10$ \\
DBP (mm Hg) & $97 \pm 5$ & $123 \pm 12$ & $95 \pm 9$ \\
MABP (mm Hg) & $110 \pm 4$ & $129 \pm 12$ & $112 \pm 9$ \\
Pulse pressure (mm Hg) & $30 \pm 6$ & $11 \pm 3^{* *}$ & $34 \pm 4^{\# \#}$
\end{tabular}

Abbreviations: DBP, mean diastolic blood pressure; IMD, intermedin; MABP, mean arterial blood pressure; SBP, mean systolic blood pressure.

The data are compared by one-way ANOVA and the comparison among groups by NewmanKeuls $t$-test. Control indicates the sham-surgery mice, I/R and I/R+IMD mean mice received ischemia/reperfusion without and with IMD treatment, respectively. ${ }^{*} P<0.05,{ }^{*} P<0.01$ vs. control; ${ }^{\#} P<0.01$ vs. I/R group. 
and area of staining ( $74.6 \pm 12.9$ vs. $3.5 \pm 0.5 \times 10^{-6}-\mu \mathrm{m}^{2}$, both $\left.n=4\right)$ were +9.0 - and +20.1 -fold (both $P<0.01$ ) higher, respectively, than those in the control group. No active IMD staining was observed in any tissue sections of negative controls treated with non-special rabbit IgG, normal goat serum instead of primary antibody.

\section{Alterations in IMD and IMD receptor subunit gene expression}

In infarcted cardiac ventricles, $3 \mathrm{~h}$ after the reperfusion, only RAMP3 (Figures $3 e$ and $\mathrm{f}$ ) mRNA levels were significantly greater compared with controls, by $+101.1 \%$. $(P<0.01)$. However, there were no significant differences in the mRNA expression levels of IMD, CRLR and RAMP2 between the mice that received reperfusion for $3 \mathrm{~h}$ and the control group (all $P>0.05$, Figures $3 \mathrm{a}, \mathrm{b}, \mathrm{d}$ and $\mathrm{f}$ ).

At $48 \mathrm{~h}$ after reperfusion, the mRNA levels of IMD, CRLR, RAMP2 and RAMP3 in infarcted hearts were much higher than those of control animals by $+239.1 \%(P<0.01),+210.9 \%(P<0.01)$, $+45.3 \%(P<0.01)$ and $+47.0 \%(P<0.05)$ (Figures $3 \mathrm{a}, \mathrm{b}, \mathrm{d}, \mathrm{e}$ and $\mathrm{f})$, respectively.

Compared with that in mice after $3 \mathrm{~h}$ of reperfusion, the mRNA expressions of IMD, CRLR and RAMP2 in the infarcted hearts $48 \mathrm{~h}$

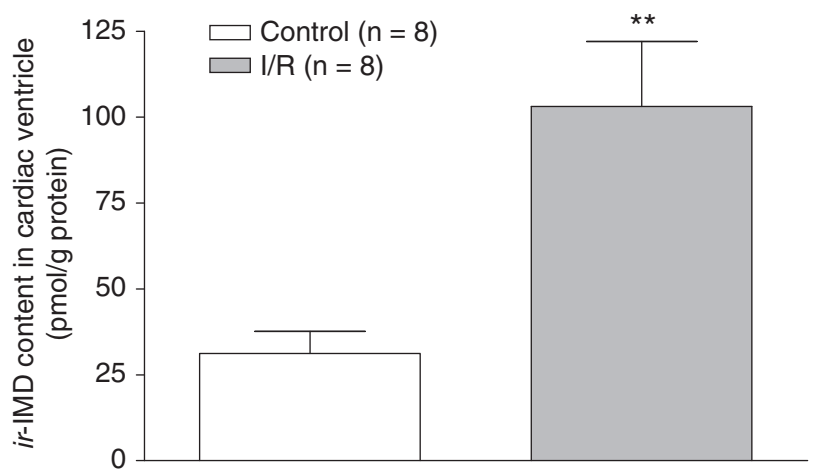

Figure 1 Changes of immunoreactive-intermedin (ir-IMD) levels in cardiac tissue of sham and infarcted mice. The data (expressed as pmol per gram protein) are mean \pm s.e.m. ( $n=8$ /group) and are compared by the use of unpaired Student's $t$-test. Control, sham-operated mice; I/R, mice receiving ischemia/reperfusion treatment. ${ }^{* *} P<0.01$ vs. control. after reperfusion were greater by $+219.7,+299.5$ and $+63.7 \%$ (all $P<0.01$, Figures $3 \mathrm{a}, \mathrm{b}, \mathrm{d}$ and $\mathrm{f}$ ), respectively. However, RAMP3 (Figures $3 \mathrm{e}$ and $\mathrm{f}$ ) mRNA expression was significantly weaker by $-26.9 \%(P<0.01)$.

No significant differences were observed in the RAMP1 mRNA levels between the control group and the ischemic mice reperfused for 3 and $48 \mathrm{~h}$ (all $\mathrm{P}>0.05$, Figures $3 \mathrm{c}$ and $\mathrm{f}$ ).

\section{IMD treatment alleviated myocardial infarct size after LAD occlusion and reperfusion}

The effect of IMD on MI/R injury is shown in Figure 4a. Gross histological analysis of 2,3,5-triphenyltetrazolium chloride-stained sections $48 \mathrm{~h}$ after reperfusion showed a much smaller necrotic area in mice after IMD treatment. Histomorphometric analysis revealed that the infarct size in IMD-treated mice was decreased by $-66.9 \%$ relative to cardiac I/R mice ( $37.5 \pm 6.3$ vs. $12.4 \pm 3.1 \%$, both $n=8$, $P<0.01$ ) (Figures $4 \mathrm{a}$ and $\mathrm{b}$ ), despite a comparable risk area in both groups (Figure $4 \mathrm{~b}$ ). We measured serum CK and LDH levels $48 \mathrm{~h}$ after reperfusion. $\mathrm{CK}$ and $\mathrm{LDH}$ activities (Figure $4 \mathrm{c}$ ) in infarcted mice were increased by +205.4 and $+155.8 \%$, respectively (both $n=8, P<0.01$ ), compared with the baseline levels $\left(291.4 \pm 101.9 \mathrm{Ul}^{-1}\right.$ for $\mathrm{CK}$ and $307.6 \pm 85.7 \mathrm{Ul}^{-1}$ for $\mathrm{LDH}$, respectively) in controls that received sham-surgery. By contrast, $\mathrm{CK}$ and $\mathrm{LDH}$ activities were markedly decreased by $-46.8 \%(n=8, P<0.01)$ and $-17.9 \%(n=8, P<0.05)$, respectively, after IMD treatment (Figure $4 \mathrm{c}$ ), compared with infarcted mice.

\section{Decreased PMN infiltration number in boundary area after IMD treatment}

One of the hallmarks of reperfusion injury is the accumulation of PMNs in the injured tissue. ${ }^{2-4}$ In fact, Watanabe et al. ${ }^{18}$ reported that $\mathrm{ADM}$, another member of the CGRP family, reduces acute ischemic brain injury by inhibiting the infiltration of neutrophils into the ischemic tissue. In this study, the comparison of infarcted mice without and with IMD treatment (Figure 5a) showed that the number of PMNs infiltrating the myocardium in the boundary area around the infarction was indeed diminished after IMD administration. Summarizing the counts from at least ten randomly selected microscope fields in the boundary area from the slides of the apex, mid-papillary and base, we found that significantly fewer PMNs were present in the
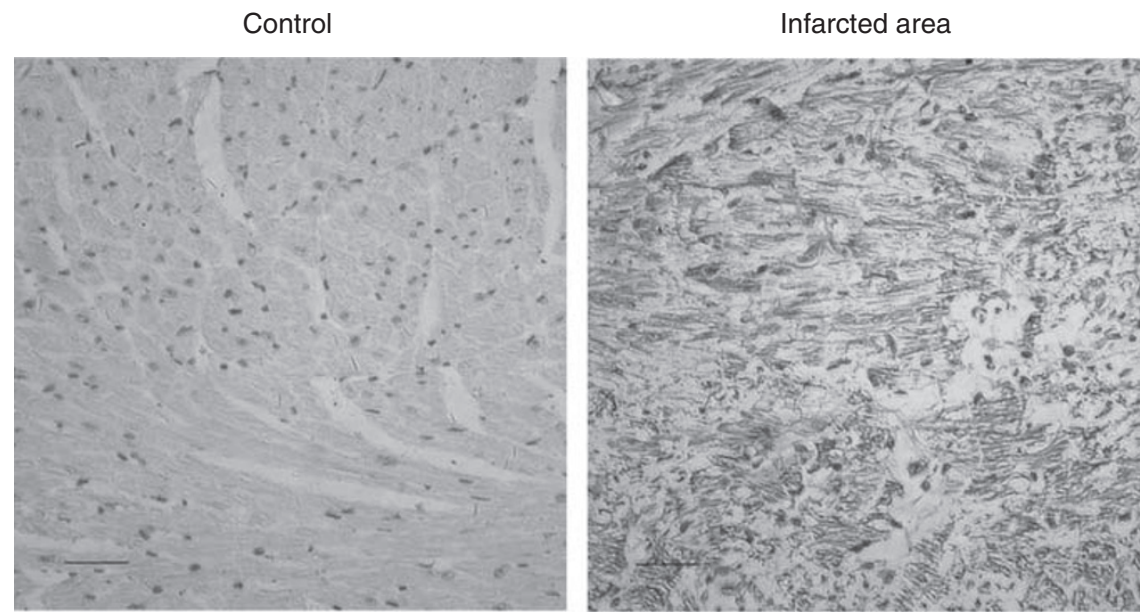

Figure 2 The immunostain of intermedin (IMD) protein in mouse cardiac ventricles ( $n=4$ per group). Representative photomicrographs $(\times 400$, the scale $\mathrm{bar}=50 \mu \mathrm{m})$ showed that after myocardial ischemia/reperfusion, a much stronger positive stain of IMD presented in the cytoplasm of myocardial cells in the infarcted area than in that of the sham-surgery control. Control, sham-operated mice; infarcted area, mice receiving ischemia/reperfusion treatment. 
myocardium after IMD treatment by $-32.7 \%$ (772 \pm 69 PMNs per $\mathrm{mm}^{2}$ vs. $519 \pm 76 \mathrm{PMNs}$ per $\mathrm{mm}^{2}$, both $n=4, P<0.05$ ) (Figure $5 \mathrm{~b}$ ).

\section{Relationship between the IMD contents in tissues and the} hemodynamic parameters

Compared with the control, mice with myocardial infarction had increased IMD concentration in plasma and cardiac ventricles. Linear regression analysis indicated positive correlations between the blood IMD content and DBP $(P<0.01)$, and between the cardiac IMD content and DBP $(P<0.01)$ and MABP $(P<0.05)(r=0.80,0.64$ and
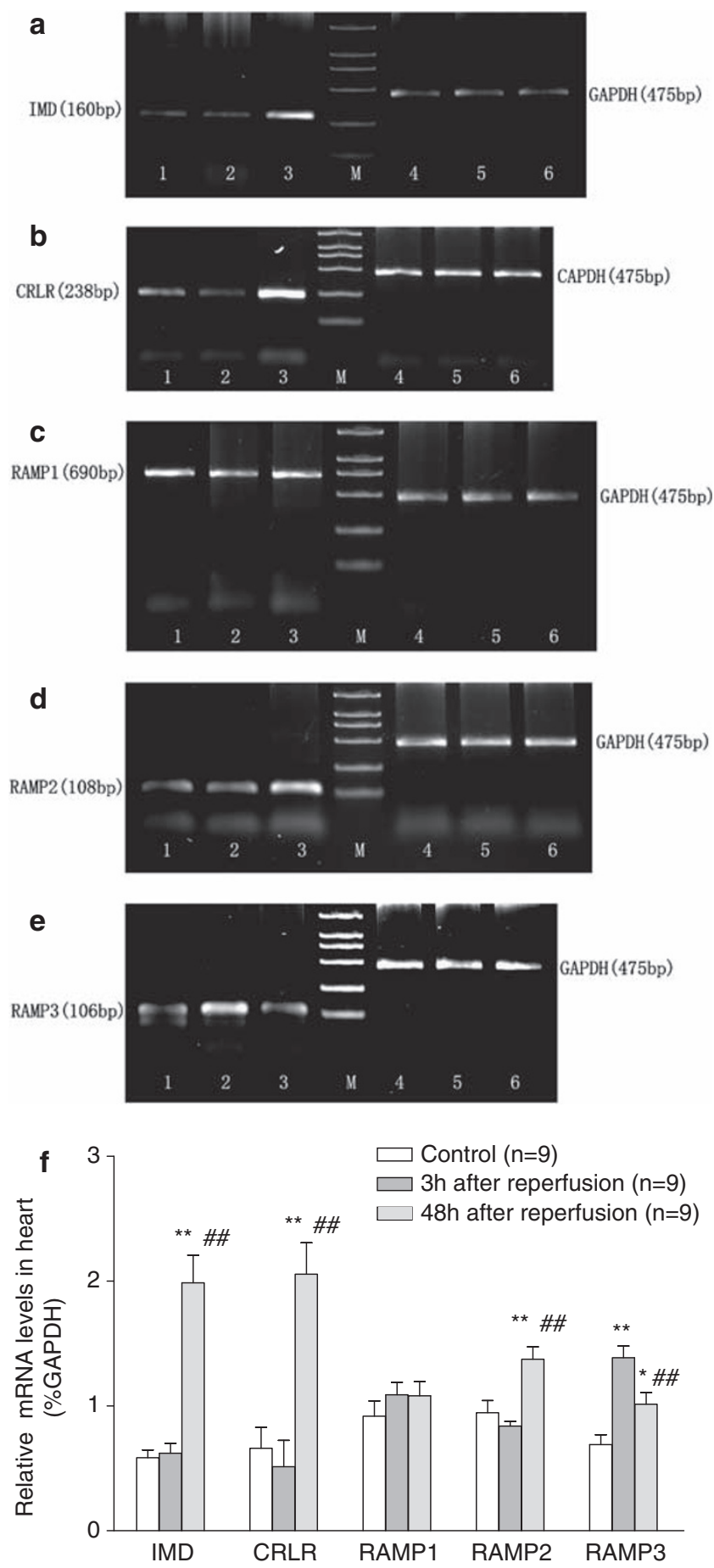

0.59 , all $n=16$, respectively). A negative correlation was observed between the blood and cardiac IMD contents and the pulse pressure ( $r=-0.63$ and $-0.53, P<0.01$ and 0.05 , both $n=16$, respectively).

\section{DISCUSSION}

Intermedin is expressed sparsely in the normal adult heart and vasculature, especially in endothelial cells. ${ }^{10} \mathrm{IMD}$ is a potent systemic and pulmonary vasodilator that is able to regulate regional blood flow and increase cardiac contractility. ${ }^{9,10}$ Plasma levels of IMD, similar to those of $\mathrm{ADM}$, are broadly similar or slightly greater in rats than in humans. ${ }^{10}$ Recently, it has been reported that IMD and its receptors were augmented in cardiovascular tissues in congestive heart failure, ${ }^{15}$ hypertension, ${ }^{14}$ chronic hypoxic pulmonary hypertension ${ }^{19}$ and chronic inhibition of nitric oxide synthesis. ${ }^{20}$ The upregulation of IMD peptide in pathological states indicates an important protective role as an endogenous auto-/paracrine factor to antagonize organ damage. ${ }^{10,20}$

After reperfusion, the intense inflammatory reaction begins in the infarcted myocardium, which may be a factor in the extension of injury. ${ }^{2,4}$ However, the inflammatory reaction is also critical to cardiac tissue repair. ${ }^{4}$ The cellular responses that mediate these functions are orchestrated by sequential induction and/or release of cytokines resulting in a closely regulated cytokine cascade. ${ }^{6}$ Mediators including interleukins, adhesion molecules and many auto-/paracrine factors, such as $\mathrm{ADM},{ }^{16,18}$ angiotensin $\mathrm{II}^{21}$ and endothelin, ${ }^{22}$ are involved in cardiac tissue inflammation, repair and scar formation., ${ }^{5,6}$ Closer structural similarity of IMD to CGRP and ADM suggests that CGRP, ADM and IMD represent an evolutionary sub-branch of the superfamily. ${ }^{9,10}$ The vasodilatory and positive inotropic properties of IMD are of particular interest in the pathophysiology of cardiovascular diseases. ${ }^{10}$ In fact, CGRP and ADM have been reported to be upregulated in plasma and cardiovascular tissues in cardiac ischemic diseases. ${ }^{16,23,24}$ They effectively antagonize the deleterious actions of angiotensin $\mathrm{II}^{25,26}$ and endothelin ${ }^{26,27}$ in different cardiovascular diseases, which indicates that IMD might counteract vicious stimuli in a similar way. ${ }^{10}$ Although the IMD gene delivery technique has not been applied to ameliorate conditions of cardiac ischemia, Hagiwara et al. $^{28}$ have fully shown that a delivered human IMD gene not only produced a sustained reduction of blood pressure but also attenuated renal dysfunction in DOCA-salt hypertensive rats by inhibition of oxidative stress and proinflammatory mediator pathways. This indicated that endogenous IMD possesses a cytoprotective effect against organ damage. In this study, we created a mouse model of MI/R in

Figure 3 Gene expressions of intermedin (IMD), its receptors and GAPDH in the left ventricle of sham and infarcted mice ( $n=3$ /group). (a) IMD gene (from lanes 1 to 3 ) and GAPDH gene (from lanes 4 to 6) expression; (b) calcitonin receptor-like receptor gene (from lanes 1 to 3 ) and GAPDH gene (from lanes 4 to 6 ) expression; (c) receptor activity-modifying protein (RAMP) 1 gene (from lanes 1 to 3 ) and GAPDH gene (from lanes 4 to 6 ) expression; (d) RAMP2 gene (from lanes 1 to 3 ) and GAPDH gene (from lanes 4 to 6 ) expression; (e) RAMP3 gene (from lanes 1 to 3 ) and GAPDH gene (from lanes 4 to 6 ) expression; Lanes 1 and 4 , the gene expressed in the control; Lanes 2 and 5 , the gene expressed in the infarcted ventricles at $3 \mathrm{~h}$ after reperfusion; Lanes 3 and 6 , the gene expressed in the infarcted ventricles at $48 \mathrm{~h}$ after reperfusion; $M$, the marker. (f) Changes of IMD, CRLR and RAMP gene expressions in cardiac ventricles of sham and infarcted mice. The data (expressed as ratios of target genes and GAPDH gene) are presented as mean \pm s.e.m. ( $n=9$ per group) and compared by one-way ANOVA and Newman-Keuls $t$-test. ${ }^{*} P<0.05, * * P<0.01$ vs. control; ${ }^{\#} P<0.01$ vs. the mice at $3 \mathrm{~h}$ after reperfusion. 
a

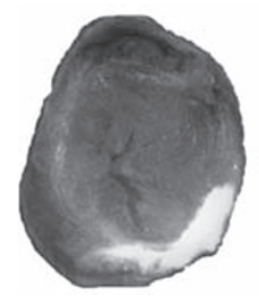

I/R

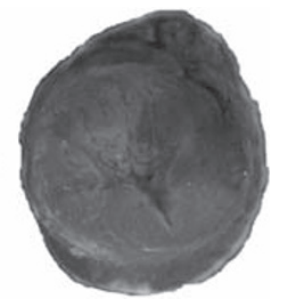

I/R+IMD
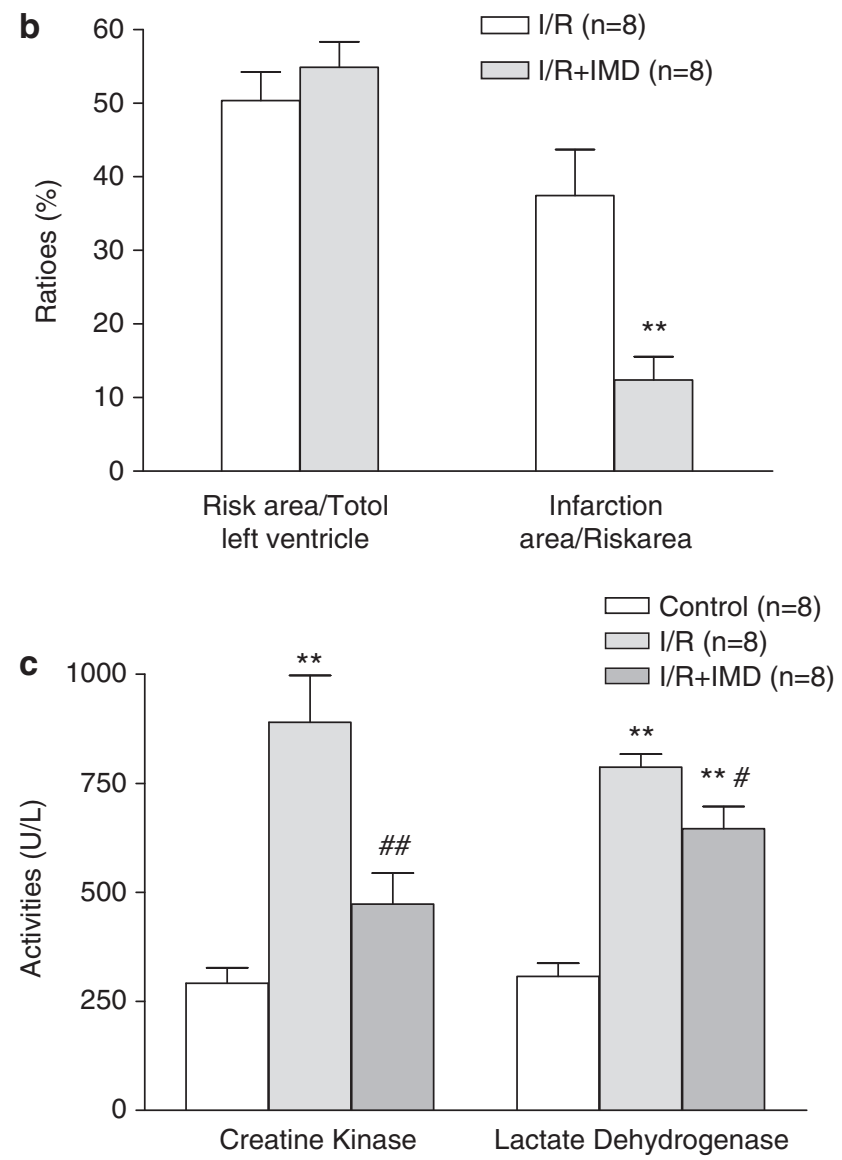

Figure 4 Effect of intermedin (IMD) administration on left ventricle (LV) infarct size after acute ischemia/reperfusion (I/R) injury. (a) Representative TTC-stained bi-ventricular thick sections from infarcted mice without and with IMD treatment at $48 \mathrm{~h}$ after reperfusion. (b) Morphometric analysis of LV area at risk and infarct size in the two groups mentioned above. (c) Serum activities of creatine kinase and lactate dehydrogenase in sham and infarcted mice without and with IMD treatment at $48 \mathrm{~h}$ after reperfusion. Control indicates sham-operated mice; I/R, mice receiving I/R treatment; I/R+IMD, mice receiving I/R together with IMD treatments. ${ }^{* *} P<0.01$ vs. I/R or control; ${ }^{\#} P<0.05,{ }^{\# \#} P<0.01$ vs. I/R group.

which pulse pressure, an important indicator of cardiac function, ${ }^{29}$ was decreased significantly $48 \mathrm{~h}$ after the reperfusion. Maintenance of vascular responsiveness to various vasoactive factors is very important in microcirculation dysfunction in cardiac ischemic diseases. ${ }^{5,6,10}$ It is still unclear how IMD changes in tissues in cardiac ischemia and other cardiovascular diseases, and whether the changed IMD has an important part in the pathogenesis of these diseases.

We observed diffuse distribution of IMD in plasma and the cardiac ventricle, which increased $48 \mathrm{~h}$ after reperfusion. These data have not

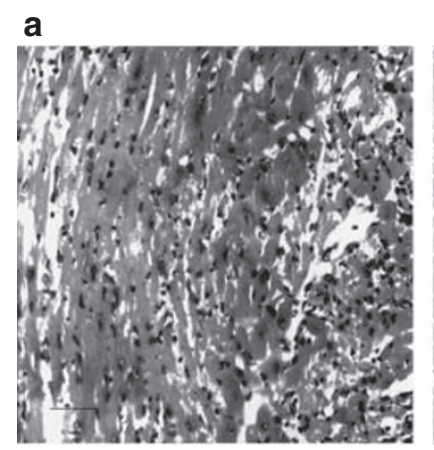

I/R

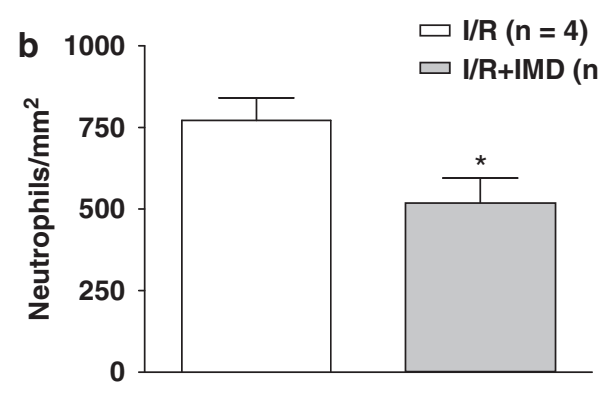

Figure 5 Effect of intermedin (IMD) administration on leukocyte infiltration. (a) Representative photomicrographs $(\times 400$, the scale bar $=50 \mu \mathrm{m})$ showing neutrophils marked by their multilobed nuclei in the peri-infarct region of the left ventricle in infarcted mice without and with IMD treatment, respectively. Arrows indicate polymorph-nuclear neutrophils. (b) Quantitative morphometric analysis of polymorph-nuclear neutrophil infiltration ( $n=4$ per group). I/R, mice receiving ischemia/reperfusion (I/R) treatment; I/R+IMD, mice receiving I/R together with IMD treatments. ${ }^{*} P<0.05$.

been reported earlier. The IMD levels in plasma and the cardiac tissue of control mice in our study were similar to those reported by Zeng et al. ${ }^{14}$ in WKY rats $\left(40.66 \pm 2.9\right.$ pmoll $^{-1}$ and $38.5 \pm 4.2 \mathrm{pmol}$ per gram protein, respectively). Blood pressure is a periodic phenomenon consisting of two components, namely steady and pulsatile. ${ }^{29}$ Pulse pressure correlates with the pulsatile component, which represents the variations of the pressure curve around the steady component and depends mostly on large artery compliance and ventricular ejection. ${ }^{29}$ In our study, pulse pressure decreased after $M I / R$, and a negative correlation was observed between it and the cardiac ir-IMD contents in the blood. This might indicate that IMD was correlated with a dysfunction of ventricular ejection. In addition, there were positive correlations between the blood IMD content and DBP, and between cardiac IMD content and DBP and MABP. As IMD induces vasodilation and positive inotropic action in regulating cardiovascular function, ${ }^{10}$ the increase in tissue IMD levels might contribute to improvements in hemodynamic response. Immunohistochemical assay indicated that compared with control, IMD expression was increased in the infarcted cardiac ventricle. Reverse transcriptasePCR analysis revealed that $48 \mathrm{~h}$ after reperfusion, the IMD mRNA level in the infarcted heart was higher than that of the sham-surgery control, which indicated that the upregulated expression of the IMD gene may induce the increase of protein expression to perform a compensatory cytoprotective response to the damaged local microcirculation.

To understand the possible cytoprotection by IMD in $M I / R$ diseases, further study was carried out by the intraperitoneal injection of IMD. We observed that IMD administration significantly ameliorated 
$\mathrm{MI} / \mathrm{R}$ injury by recovering the pulse pressure, decreasing the infarction area, $\mathrm{CK}$ and $\mathrm{LDH}$ activities, and inhibiting the infiltration of neutrophils into the peri-infarction area. Our results were compatible with those reported by Yang et al., ${ }^{30}$ who found, using a Langendorrf set, that IMD offered clear protection against the cardiac I/R injury of rat tissue in vitro. The authors also indicated that IMD might be a beneficial local endogenous factor to antagonize cardiac ischemic injury.

IMD shares a family of receptors with ADM and CGRP, each of which is composed of a CRLR associated with one of the three RAMPs. ${ }^{9,10}$ RAMPs act as molecular chaperones for trafficking CRLR, and they show varying degrees of affinity for CRLR in the different cell types in which they are coexpressed. ${ }^{10}$ Compared with CGRP, IMD has less affinity for CGRP1 receptors (CRLR/RAMP1) but more affinity for ADM1 receptors (CRLR/RAMP2) and ADM2 receptors (CRLR/RAMP3); ${ }^{8,9}$ compared with ADM, IMD has more affinity for CGRP1 receptors but less affinity for CRLR/RAMP2 and CRLR/RAMP3 receptors. ${ }^{8,9}$ IMD acutely augments cardiomyocyte contractile function through a protein kinase $\mathrm{C}$ - and protein kinase A-dependent mechanism, ${ }^{31}$ and relaxes the rat's main pulmonary arterial rings through a cGMP-dependent pathway. ${ }^{32}$ By using reverse transcriptase-PCR assay, we observed that in the mouse cardiac ventricle, $3 \mathrm{~h}$ after the reperfusion, only the mRNA expression level of the RAMP3 gene was elevated. However, $48 \mathrm{~h}$ after reperfusion, the mRNA levels of CRLR, RAMP2 and RAMP3 were all higher compared with those in control animals. These results are similar to those obtained in studies of rats. ${ }^{33}$ Considering that IMD is a selective agonist for CRLR/RAMP1 and CRLR/RAMP3 receptors, ${ }^{9,11}$ our results indicate that in cardiac infarct diseases, following the upregulation of CRLR and RAMP3 gene expression, the action of the IMDCRLR/RAMP3 receptor pathway may be potentiated very early after reperfusion.

The concentrations of IMD in blood and local tissues are regulated by the balance between its production and degradation. ${ }^{10,34} \mathrm{We}$ observed that IMD mRNA and protein expression increased in ischemic cardiac tissue. It is well known that IMD mRNA expression, synthesis and secretion are upregulated by a few stimuli, such as estrogen, ${ }^{11}$ oxidative stress, ${ }^{12}$ pressure loading and ischemic insult. ${ }^{20}$ The factors involved in cardiac ischemic diseases, including catecholamines, angiotensin II, endothelin-1 and numerous cytokines, might upregulate IMD gene expression. ${ }^{4,5}$ Bell et al. ${ }^{12}$ reported that the local concentration and action of IMD may be further enhanced by the downregulation of neutral endopeptidase, a membrane-bound metallopeptidase that may degrade IMD in local tissues. Further studies are needed to confirm the regulation of IMD expression by hypoxia and the change in the activity of neutral endopeptidase in local ischemic tissues.

In summary, our study evaluated the concentrations, and mRNA and protein expression of IMD, as well as the mRNA expressions of its receptors, in blood and cardiac tissue with myocardial ischemic insult. The treatment of the infarcted mice with exogenous IMD was also studied. Compared with the control group, infarcted animals showed increased expression and concentration of IMD in plasma and cardiac tissue, and the changes in the plasma and cardiac ir-IMD contents were correlated with blood and pulse pressures. In addition, the exogenous IMD treatment significantly ameliorated the cardiac injury, inhibited the neutrophil infiltration and recovered the pulse pressure. In the infarcted heart, mRNA expressions of the RAMP3 and CRLR genes increased in the early and late stage of reperfusion, respectively. Our results indicate that IMD is upregulated in cardiac I/R diseases, which might induce important beneficial effects against cardiac injury and inflammatory reaction through the augmentation of the IMDCRLR/RAMP3 receptor pathway. The pathophysiological role of IMD in cardiac ischemia, as well as the reasons for tissue concentration changes of IMD and its receptors, warrants further study.

\section{ACKNOWLEDGEMENTS}

This work was supported by grants from the Sichuan University Foundation for Youths (07067) and the National Natural Science Foundation of China (30871017) to Dr Wei Jiang.

1 Moens AL, Claeys MJ, Timmermans JP, Vrints CJ. Myocardial ischemia/reperfusioninjury, a clinical view on a complex pathophysiological process. Int J Cardiol 2005; 100: $179-190$.

2 Buja LM. Myocardial ischemia and reperfusion injury. Cardiovasc Pathol 2005; 14: 170-175.

3 Jiang W, Hall SR, Moos MP, Cao RY, Ishii S, Ogunyankin KO, Melo LG, Funk CD. Endothelial cysteinyl leukotriene 2 receptor expression mediates myocardial ischemiareperfusion injury. Am J Pathol 2008; 172: 592-602.

4 Di Napoli P, Taccardi AA, De Caterina R, Barsotti A. Pathophysiology of ischemiareperfusion injury: experimental data. Ital Heart J 2002; 3(Suppl 4): 24S-28S.

5 Prabhu SD. Cytokine-induced modulation of cardiac function. Circ Res 2004; 95 : 1140-1153.

6 Frangogiannis NG, Youker KA, Rossen RD, Gwechenberger M, Lindsey $M H$, Mendoza LH, Michael LH, Ballantyne CM, Smith CW, Entman ML. Cytokines and the microcirculation in ischemia and reperfusion. J Mol Cell Cardiol 1998; 30: 2567-2576.

7 Foster D, Parrish-Novak J, Fox B, Xu W. Cytokine-receptor pairing: accelerating discovery of cytokine function. Nat Rev Drug Discov 2004; 3: 160-170.

8 Roh J, Chang CL, Bhalla A, Klein C, Hsu SY. Intermedin is a calcitonin/calcitonin generelated peptide family peptide acting through the calcitonin receptor-like receptor/ receptor activity-modifying protein receptor complexes. J Biol Chem 2004; 279: 7264-7274.

9 Chang CL, Roh J, Hsu SY. Intermedin, a novel calcitonin family peptide that exists in teleosts as well as in mammals: a comparison with other calcitonin/intermedin family peptides in vertebrates. Peptides 2004; 25: 1633-1642.

10 Bell D, McDermott BJ. Intermedin (adrenomedullin-2): a novel counter-regulatory peptide in the cardiovascular and renal systems. Br J Pharmacol 2008; 153(Suppl 1): S247-S262

11 Chang CL, Roh J, Park JI, Klein C, Cushman N, Haberberger RV, Hsu SY. Intermedin functions as a pituitary paracrine factor regulating prolactin release. Mol Endocrinol 2005; 19: 2824-2838

12 Bell D, Zhao Y, McCoy FP, Devine A, McDermott BJ. Expression of the counterregulatory peptide intermedin is augmented in the presence of oxidative stress in hypertrophied cardiomyocytes. Cell Physiol Biochem 2008; 21: 409-420.

13 Zhao Y, Bell D, Smith LR, Zhao L, Devine AB, McHenry EM, Nicholls DP, McDermott BJ. Differential expression of components of the cardiomyocyte adrenomedullin/intermedin receptor system following blood pressure reduction in nitric oxide-deficient hypertension. J Pharmacol Exp Ther 2006; 316: 1269-1281.

14 Zeng Q, Yuan Y, Wang X, Wu HM, Fan L, Qi YF, Tang CS, Cai Y, Pan CS. Upregulated expression of intermedin and its receptor in the myocardium and aorta in spontaneously hypertensive rats. Peptides 2009; 30: 391-399.

15 Hirose T, Totsune K, Mori N, Morimoto R, Hashimoto M, Nakashige Y, Metoki H, Asayama K, Kikuya M, Ohkubo T, Hashimoto J, Sasano H, Kohzuki M, Takahashi K, Imai $Y$. Increased expression of adrenomedullin 2/intermedin in rat hearts with congestive heart failure. Eur J Heart Fail 2008; 10: 840-849.

16 Jiang W, Jiang HF, Pan CS, Cai DY, Qi YF, Pang YZ, Tang CS. Relationship between the contents of adrenomedullin and distributions of neutral endopeptidase in blood and tissues of spontaneously hypertensive rats. Hypertens Res 2004; 27: 109-117.

17 Izumi T, Saito Y, Kishimoto I, Harada M, Kuwahara K, Hamanaka I, Takahashi N, Kawakami R, Li Y, Takemura G, Fujiwara H, Garbers DL, Mochizuki S, Nakao K. Blockade of the natriuretic peptide receptor guanylyl cyclase-A inhibits NF-kB activation and alleviates myocardial ischemia/reperfusion injury. J Clin Invest 2001; 108: 203-213.

18 Watanabe K, Takayasu M, Noda A, Hara M, Takagi T, Suzuki Y, Yoshia J. Adrenomedullin reduces ischemic brain injury after transient middle cerebral artery occlusion in rats. Acta Neurochir (Wien) 2001; 143: 1157-1161.

19 Gong YS, Fan XF, Wu XM, Hu LG, Tang CS, Pang YZ, Qi YF. Changes of intermedin/ adrenomedullin 2 and its receptors in the right ventricle of rats with chronic hypoxic pulmonary hypertension. Sheng Li Xue Bao 2007; 59: 210-214.

20 Bell D, Zhao YY, Devine AB, McDermott BJ. Influence of atenolol and nifedipine on nitric-oxide deficient cardiomyocyte hypertrophy and expression of the cardio-endocrine peptide intermedin and its receptor components. Cell Physiol Biochem 2008; 21: 203-214.

21 Booz GW, Day JN, Baker KM. Interplay between the cardiac renin angiotensin system and JAK-STAT signaling: role in cardiac hypertrophy, ischemia/reperfusion dysfunction, and heart failure. J Mol Cell Cardiol 2002; 34: 1443-1453. 
22 Brunner F. Interaction of nitric oxide and endothelin-1 in ischemia/reperfusion injury of rat heart. J Mol Cell Cardiol 1997; 29: 2363-2374.

23 Källner G. Release and effects of calcitonin gene-related peptide in myocardial ischaemia. Scand Cardiovasc J Suppl 1998; 49: 1-35.

24 Yin H, Chao L, Chao J. Adrenomedullin protects against myocardial apoptosis after ischemia/reperfusion through activation of Akt-GSK signaling. Hypertension 2004; 43 : 109-116.

$25 \mathrm{Li} \mathrm{J}$, Wang DH. Development of angiotensin II-induced hypertension: role of CGRP and its receptor. J Hypertens 2005; 23: 113-118.

26 Luodonpää M, Vuolteenaho O, Eskelinen S, Ruskoaho H. Effects of adrenomedullin on hypertrophic responses induced by angiotensin II, endothelin-1 and phenylephrine. Peptides 2001; 22: 1859-1866.

27 Wang Y, Wang DH. Prevention of endothelin-1-induced increases in blood pressure: role of endogenous CGRP. Am J Physiol Heart Circ Physiol 2004; 287: H1868-H1874.

28 Hagiwara M, Bledsoe G, Yang ZR, Smith Jr RS, Chao L, Chao J. Intermedin ameliorates vascular and renal injury by inhibition of oxidative stress. Am J Physiol Renal Physiol 2008; 295: F1735-F1743.

29 Voors AA, Petrie CJ, Petrie MC, Charlesworth A, Hillege HL, Zijlstra F, McMurray JJ, van Veldhuisen DJ. Low pulse pressure is independently related to elevated natriuretic peptides and increased mortality in advanced chronic heart failure. Eur Heart J 2005; 26: 1759-1764.

30 Yang JH, Jia YX, Pan CS, Zhao J, Ouyang M, Yang J, Chang JK, Tang CS, Qi YF. Effects of intermedin(1-53) on cardiac function and ischemia/reperfusion injury in isolated rat hearts. Biochem Biophys Res Commun 2005; 327: 713-719.

31 Dong F, Taylor MM, Samson WK, Ren J. Intermedin (adrenomedullin-2) enhances cardiac contractile function via a protein kinase $\mathrm{C}$ - and protein kinase A-dependent pathway in murine ventricular myocytes. J App/ Physiol 2006; 101: 778-784.

32 Kandilci HB, Gumusel B, Lippton H. Intermedin/adrenomedullin-2 (IMD/AM2) relaxes rat main pulmonary arterial rings via cGMP-dependent pathway: role of nitric oxide and large conductance calcium-activated potassium channels (BK(Ca)). Peptides 2008; 29: 1321-1328.

33 Oie E, Vinge LE, Andersen GØ, Yndestad A, Krobert KA, Sandberg C, Ahmed MS, Haug T, Levy FO, Skomedal T, Attramadal H. RAMP2 and RAMP3 mRNA levels are increased in failing rat cardiomyocytes and associated with increased responsiveness to adrenomedullin. J Mol Cell Cardiol 2005; 38: 145-151.

34 Hirata Y, Mitaka C, Sato K, Nagura T, Tsunoda Y, Amaha K, Marumo F. Increased circulating adrenomedullin, a novel vasodilatory peptide, in sepsis. J Clin Endocrinol Metab 1996; 81: 1449-1453. 